\title{
Glucose principally regulates insulin secretion in mouse islets by controlling the numbers of granule fusion events per cell
}

\author{
Jiun T. Low • Justin M. Mitchell • Oanh H. Do • Jacinda Bax • \\ Alicia Rawlings • Michael Zavortink • Garry Morgan • \\ Robert G. Parton • Herbert Y. Gaisano • Peter Thorn
}

Received: 6 June 2013 / Accepted: 19 July 2013 / Published online: 1 September 2013

(C) The Author(s) 2013. This article is published with open access at Springerlink.com

\begin{abstract}
Aims/hypothesis In dispersed single beta cells the response of each cell to glucose is heterogeneous. In contrast, within an islet, cell-to-cell communication leads to glucose inducing a more homogeneous response. For example, increases in $\mathrm{NAD}(\mathrm{P}) \mathrm{H}$ and calcium are relatively uniform across the cells of the islet. These data suggest that secretion of insulin from single beta cells within an islet should also be relatively homogeneous. The aim of this study was to test this hypothesis by determining the glucose dependence of single-cell insulin responses within an islet.

Methods Two-photon microscopy was used to detect the glucose-induced fusion of single insulin granules within beta cells in intact mouse islets.

Results First, we validated our assay and showed that the measures of insulin secretion from whole islets could be explained by the time course and numbers of granule fusion events observed. Subsequent analysis of the patterns of granule fusion showed that cell recruitment is a significant factor, accounting for a fourfold increase from 3 to $20 \mathrm{mmol} / \mathrm{lglu}$ cose. However, the major factor is the regulation of the
\end{abstract}

Electronic supplementary material The online version of this article (doi:10.1007/s00125-013-3019-5) contains peer-reviewed but unedited supplementary material, which is available to authorised users.

J. T. Low $\cdot$ J. M. Mitchell $\cdot$ O. H. Do $\cdot$ J. Bax $\cdot$ A. Rawlings $\cdot$

M. Zavortink $\cdot$ P. Thorn $(\bowtie)$

School of Biomedical Sciences, University of Queensland,

St Lucia, QLD 4072, Australia

e-mail: p.thorn@uq.edu.au

G. Morgan · R. G. Parton

Institute of Molecular Bioscience, University of Queensland,

St Lucia, QLD, Australia

H. Y. Gaisano

Department of Medicine, University of Toronto,

Toronto, ON, Canada numbers of granule fusion events within each cell, which increase ninefold over the range of 3 to $20 \mathrm{mmol} / 1$ glucose. Further analysis showed that two types of granule fusion event occur: 'full fusion' and 'kiss and run'. We show that the relative frequency of each type of fusion is independent of glucose concentration and is therefore not a factor in the control of insulin secretion.

Conclusions/interpretation Within an islet, glucose exerts its main effect through increasing the numbers of insulin granule fusion events within a cell.

Keywords Insulin $\cdot$ Islet $\cdot$ Secretion

Abbreviations
$\begin{array}{ll}\text { HPTS } & \text { Hydroxypyrene-3,6,8-trisulfonate } \\ \text { HRP } & \text { Horseradish peroxidase } \\ \text { SRB } & \text { Sulforhodamine B }\end{array}$

\section{Introduction}

Isolated single beta cells have a heterogeneous response to glucose. This has been recorded for glucose-stimulated protein biosynthesis as reported by amino acid incorporation [1, 2], glucose metabolism [3], calcium responses [4] and for insulin secretion [5]. As the glucose concentration is increased, the proportion of cells recruited to respond increases. For example, across the dose range 1 to $20 \mathrm{mmol} / \mathrm{l}$, glucose induces a 14-fold increase in the number of cells incorporating leucine [1], and an eightfold increase in the number of cells secreting insulin [5]. These fold changes approximately account for the observed increase in insulin secretion in islets [6] and suggest that differential sensitivities to glucose of individual cells underlie the glucose dose dependence in islets [7]. In situ support for this is shown by a heterogeneous glucose 
response of cells within islets in terms of leucine uptake [1] and heterogeneous activation of the insulin promoter [8].

However, direct comparison of insulin secretion shows there are differences in islets compared with single cells. Single cells secrete more basal insulin and respond to glucose with lower levels of secretion compared with islets $[9,10]$. Single cells also show greater capacitance changes in response to stimulation than expected from the secretory response of cells within an islet [11]. The basis of these differences is likely to be cell-to-cell communication within the islet [10], with a major factor being gap junctional links between beta cells [12]. Such cell-to-cell coupling leads to coordination between beta cells with more homogeneous cellular responses as measured by $\mathrm{NAD}(\mathrm{P}) \mathrm{H}$ activity [13] and cell calcium signals $[14,15]$. The prediction of this work is that, if we could measure the single-cell secretory responses within an islet, they should also be coordinated. However, to date in situ measurement of insulin secretion within islets has not been possible.

In the stimulus-secretion coupling pathway, calcium is the last step that triggers insulin granule fusion [16]. Measurement of the intracellular calcium response within islets, and in beta cell clusters, shows complexity in space, time and amplitude $[4,14,17]$. This makes it difficult to extrapolate from the observed calcium signals and estimate the secretory response. Therefore, while the calcium responses seem coordinated and relatively uniform within individual cells across an islet, this does not necessarily mean that insulin secretion is also uniform.

As well as driving the fusion of more granules, glucose may also regulate the dynamics of insulin granule fusion. Such complexities in the dynamics of the fusion pore that forms between the insulin granule and the cell membrane have been observed and have led to ideas that control of the fusion pore regulates the output of insulin and other granule contents, such as ATP $[18,19]$. In chromaffin cells these differences in granule fusion dynamics play a direct physiological role in the regulation of adrenaline (epinephrine) secretion [20]. The possible relevance of granule fusion dynamics is, however, controversial in beta cells. Supporting evidence comes from studies on single cells $[18,19]$. In contrast, recordings from intact islets suggest that complex granule fusion dynamics are rarely observed $[21,22]$. If the fusion pore was under the control of glucose, this could exert an additional effect on the regulation of insulin secretion.

To gain an understanding of the control glucose exerts on insulin secretion in an islet we need methods to study singlecell secretion from beta cells within an intact islet. The only method currently available is an indirect fluorescence assay that uses two-photon microscopy to track the entry of extracellular fluorescent dye into each granule as it fuses with the cell membrane $[22,23]$. This method has been successfully used to measure the responses to high levels of stimulation (forskolin and high glucose [22]). However, it has not been employed to measure the response to more physiologically relevant stimuli and has not been completely validated to determine if it is a method that can be used to accurately determine the single-granule basis of glucose-dependent insulin secretion.

In this study we have employed two-photon microscopy to measure single insulin granule fusion within single beta cells in intact islets. We have shown that the time course and extent of single granule fusion events is consistent with measures of insulin secretion from whole islets. We then studied the patterns of granule fusion across a range of glucose concentrations and determined that although cell recruitment is a factor, the major influence of glucose is to increase the numbers of granule fusion events within each single beta cell. In a development of the method we measure 'kiss-and-run' fusion events and show that this type of fusion is present but independent of glucose concentration.

\section{Methods}

Experimental solutions Experiments were performed in $\mathrm{Na}-$ rich solution $\left(\mathrm{NaCl} 140 \mathrm{mmol} / \mathrm{l}, \mathrm{KCl} 5 \mathrm{mmol} / \mathrm{l}, \mathrm{MgCl}_{2}\right.$ $1 \mathrm{mmol} / \mathrm{l}, \mathrm{CaCl}_{2} 2.5 \mathrm{mmol} / \mathrm{l}, \mathrm{NaHCO}_{3} 5 \mathrm{mmol} / \mathrm{l}$, HEPES $5 \mathrm{mmol} / \mathrm{l}, 3-20 \mathrm{mmol} / \mathrm{l}$ glucose as indicated), adjusted to pH 7.4 with $\mathrm{NaOH}$.

Islet preparation $\mathrm{CD} 1$ mice were obtained from a University of Queensland breeding colony. The mice were humanely killed according to local University of Queensland animal ethics procedures (approved by the University of Queensland, Anatomical Biosciences Ethics Committee). Isolated mouse pancreatic tissue was prepared by a collagenase (type IV) (Worthington, Lakewood, NJ, USA) digestion method in Hanks buffer (Sigma-Aldrich, Castle Hill, NSW, Australia), adjusted to $\mathrm{pH} 7.4$ with $\mathrm{NaOH}$. Isolated islets were maintained $\left(37^{\circ} \mathrm{C}, 95 / 5 \%\right.$ air/ $\left.\mathrm{CO}_{2}\right)$ in RPMI-1640 culture medium (Sigma-Aldrich) supplemented with 10\% FBS (Gibco, Life Technologies, Mulgrave, VIC, Australia), and $100 \mathrm{U} / \mathrm{ml}$ penicillin $/ 0.1 \mathrm{mg} / \mathrm{ml}$ streptomycin (Invitrogen, Life Technologies, Mulgrave, VIC, Australia).

Islet imaging Isolated islets of Langerhans were cultured for 2-3 days and then, prior to imaging, were bathed in an Na-rich solution containing $3 \mathrm{mmol} / 1$ glucose for $30 \mathrm{~min}\left(37^{\circ} \mathrm{C}\right.$, $95 / 5 \%$ air $/ \mathrm{CO}_{2}$ ). Two-photon imaging was performed at $34^{\circ} \mathrm{C}$, with exocytic events recorded as the entry of extracellular dye into each fused granule (Fig. 1).

Two-photon imaging We used a custom-made, video-rate, two-photon microscope with a $\times 60$ oil immersion objective (NA 1.42, Olympus; Olympus Australia, Mt Waverley, VIC, 

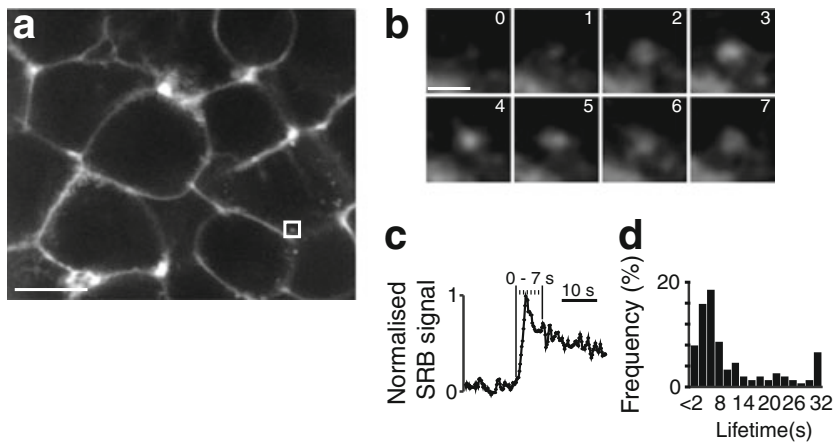

Fig. 1 Two-photon detection of single granule fusion events. (a) A twophoton cross-section through the core (three cells deep into the islet) of a single islet. Extracellular SRB dye outlines each cell and when stimulated with glucose $(8 \mathrm{mmol} / \mathrm{l})$ granule fusion leads to the appearance of bright spots of fluorescence (see fluorescent spot in the region bounded by a box). Scale bar, $10 \mu \mathrm{m}$. (b) These fusion events arise suddenly and remain for many seconds, as shown in the time-series images (enlarged from the square region highlighted in the low-magnification image) and taken at $1 \mathrm{~s}$ intervals as indicated on the graph in (c). Scale bar, $1 \mu \mathrm{m}$. (c) The plot of time against the SRB fluorescence in a region of interest placed over the granule. (d) A histogram plotting frequency against event lifetime shows a distribution of lifetimes. See also ESM Figs 1 and 2

Australia), providing an axial resolution (full width, half maximum) of $\sim 1 \mu \mathrm{m}$. We imaged exocytic events using sulforhodamine B (SRB; $800 \mu \mathrm{mol} / \mathrm{l})$ as a membraneimpermeant fluorescent extracellular marker excited by femtosecond laser pulses at $950 \mathrm{~nm}$, with fluorescence emission detected at 550-650 nm. Hydroxypyrene-3,6,8-trisulfonate (HPTS) was imaged using excitation at $950 \mathrm{~nm}$ and emission detected at $420-520 \mathrm{~nm}$.

Images (resolution of 10 pixels $/ \mu \mathrm{m}$ ) were analysed with the Metamorph program (Molecular Devices, Sunnyvale, CA, USA). Exocytic event kinetics were measured from regions of interest $\left(0.78 \mu \mathrm{m}^{2}, 78\right.$ pixels $)$ centred over individual granules. Traces were rejected if extensive movement was observed.

Electron microscopy Islets were washed in warmed PBS, then washed in $2.5 \%$ (wt/vol.) glutaraldehyde and fixed using a pressurised microwave system. Fixed islets were processed into epoxy resin. Pelleted islets were sliced at $60 \mathrm{~nm}$ (ultra-microtome) and viewed using a JOEL1010 electron microscope (Joel Australasia, Frenchs Forest, NSW, Australia).

Insulin secretion Four islets were counted, placed in a chamber in extracellular solution containing $3 \mathrm{mmol} / 1$ glucose at $37^{\circ} \mathrm{C}$, with $\mathrm{O}_{2} / \mathrm{CO}_{2}(95 / 5 \%)$, for $30 \mathrm{~min}$. They were then stimulated by the addition of glucose to the extracellular solution containing $0.2 \%$ BSA. The supernatant fraction was sampled and insulin measured using a homogeneous timeresolved fluorescence assay (Cisbio, catalogue number 62INSPEB; Genesearch, Arundel, QLD, Australia) and an anti-insulin antibody plate reader (Tecan, Infinite F200 Pro;
Tecan, Port Melbourne, VIC, Australia). Insulin concentrations were calculated using a standard curve.

Statistical analyses All numerical data are presented as mean \pm SEM. Statistical analysis was performed using Microsoft Excel and GraphPad Prism. Data sets with just two groups were subjected to a two-tailed, unpaired Student's $t$ test. Islets from at least three animals were used in each experiment.

\section{Results}

Single granule fusion events in islets show glucose dependence Isolated mouse pancreatic islets were bathed in Na-rich solution containing the fluorescent dye SRB and imaged with twophoton microscopy. Figure 1a shows the dye outlining each cell. We recorded three cell layers into the islet: a depth in a rodent islet at which most cells are beta cells [24]. With our imaging parameters, a two-photon section records an area that, on average, includes 24 cells and a section depth of $1 \mu \mathrm{m}$. We recorded at $34^{\circ} \mathrm{C}$ and tracked SRB entry into each granule as it fused with the cell membrane (Fig. 1b). Control experiments show the recorded events had the same diameter as expected for insulin granules and co-localisation of extracellular dye within fused granules with insulin (Electronic supplementary material [ESM] Figs 1 and 2).

Histogram plots of the apparent granule lifetimes measured from the middle of the rising phase of the SRB signal until the time when the fluorescence signal was indistinguishable from the baseline fluorescence (i.e. the point of granule collapse) revealed modal granule lifetimes of 4-6 s (Fig. 1d, $n=121$ exocytic events). This suggests that our temporal sampling (3-5 frames per second) resolves the real time course of granule fusion events. Previous work measured the opening phase of the fusion pore at $1.8 \mathrm{~s}$ [22], which is a measure of the time taken for dye to enter the granule lumen. Our slightly longer durations reflect measurement of the total granule lifetime, which includes the decay phase. We note here that these measures of fluorescent dye changes do not reflect the much faster kinetics of fusion-pore opening.

The key distinguishing characteristic of beta cell secretion is its glucose dependence. To measure this we switched from using $3 \mathrm{mmol} / \mathrm{l}$ glucose to solutions containing more glucose. Each islet was exposed to only one concentration of glucose and two-photon microscopy then recorded each granule fusion event over $20 \mathrm{~min}$. Figure 2 shows typical examples of responses obtained at glucose concentrations between 3 and $20 \mathrm{mmol} / \mathrm{l}$ ( $3 \mathrm{mmol} / 1$ glucose, eight islets; $6 \mathrm{mmol} / 1$ glucose, 12 islets; $8 \mathrm{mmol} / 1$ glucose, eight islets; $15 \mathrm{mmol} / \mathrm{l}$, ten islets; and $20 \mathrm{mmol} / 1$ glucose, 12 islets). The figure shows the cells outlined by the extracellular dye with the regions where each 


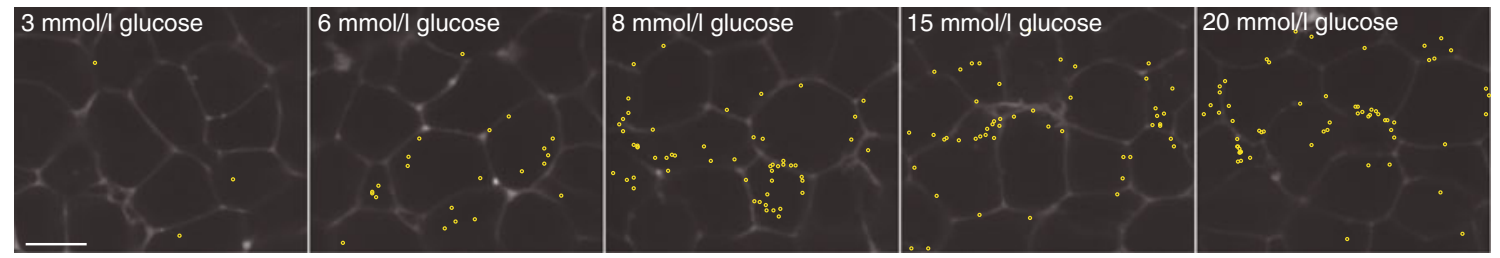

Fig. 2 Glucose dose dependently increases the number of granule fusion events. Examples of image areas taken from separate islets challenged with 3, 6, 8, 15 and $20 \mathrm{mmol} / \mathrm{l}$ glucose. In each case the image shows the

exocytic event occurred identified by yellow circles. As expected, increasing numbers of fusion events were observed at higher glucose concentrations. Fusion events at the edge of the cells were due to fusion with the cell membrane lying perpendicular to the two-photon cross-section. Fusion events that occurred apparently in the middle of the cells were due to fusion with cell membrane lying above, or below, the plane of focus.

Simple geometry (assuming spherical cells, see ESM text) shows that the area of membrane sampled was the same regardless of where in the cell the cross-section was made. In this way cells 'cut' in smaller cross-section have the same membrane area as those 'cut' in larger cross-section. We therefore sampled from similar areas of cell membrane wherever the two-photon optical slice passed through the cells. There is an exception to this, because it assumes the twophoton depth passes fully through a cell. A two-photon section at the very top or bottom of a cell might have an excitation depth that only partially penetrates the cell and the sampled membrane area would be consequently smaller. We estimate these partial sections accounted for only around $10 \%$ of all the cell cross-sections and therefore were a minor component in our measurements. In support of these calculations direct measurement shows no correlation between the apparent perimeter of a cell in the twophoton slice and the number of exocytic events observed within that cell (ESM Fig. 3).

A histogram of the total number of fusion events (Fig. 3a) shows a dose-dependent 15 -fold increase from low to high glucose. The average time course of the cumulative appearance of exocytic events (Fig. 3a) shows that increasing glucose concentration decreases the latency to the first event and increases the number of exocytic events over time (Fig. 3a). Together, these data are consistent with the expected glucosedriven fusion of insulin granules in beta cells.

We note here that, across all the glucose concentrations, our observations of exocytosis are consistent with the fusion of a population of granules of the same size. We did not see larger fusion events that might indicate compound exocytosis. This is consistent with previous observations that compound exocytosis is rare [22] and only significantly occurs in the presence of other stimuli such as glucagon-like peptide 1 (GLP-1) [25] or carbachol [26]. islets at the beginning of the $20 \mathrm{~min}$ recording period. Image analysis was used to identify each fusion event and the position of each one is indicated by the yellow circles on the images. Scale bar, $10 \mu \mathrm{m}$

Increasing glucose concentration drives increases in the number of responding cells and granule fusion events within a cell We used the spatial and temporal resolution of our recordings to determine the nature of the glucose-driven increase in granule fusion events at the cellular level. First, we analysed the numbers of responding cells. From our images many cells showed insulin granule fusion events and, as the
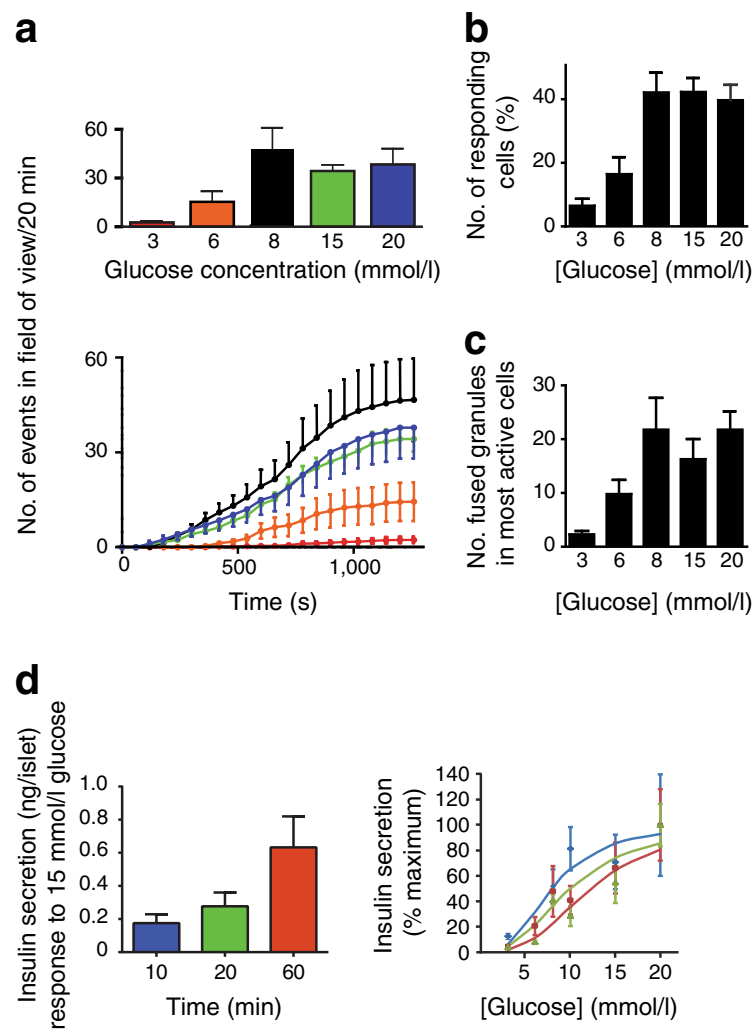

Fig. 3 The glucose-dependent increase in secretion is predominantly due to recruitment within focal regions of exocytosis. (a) Data from all experiments (in Fig. 2): the bar chart counts the total average number of fusion events and the line graph plots the cumulative average time course of the appearance of the fusion events (error bars are SEM). (b) The mean \pm SEM of the apparent number of responding cells within the two-photon section. (c) The total number of exocytic events, recorded over the $20 \mathrm{~min}$ period after glucose application, within the four best responding cells at each glucose concentration. (d) Measures of glucose-stimulated insulin secretion show a time-dependent increase in insulin secreted (bar chart) and a rightward shift in the dose-response curve at increasing times in glucose (line graph). Blue, $10 \mathrm{~min}$; green, $20 \mathrm{~min}$; and red, $60 \mathrm{~min}$ 
glucose concentration increased, the number of recruited cells increased (Fig. 3b). As our two-photon slices sample less than $10 \%$ of the total area of the cell membrane we suggest that the apparently non-responding cells are likely to be responding in regions outside of our sampled area. A quantitative assessment of granule numbers therefore requires a method to identify all granule fusion events within one cell, something that is not technically possible at the moment. Nevertheless, our aim here was to understand the targets for glucose-induced recruitment of granules. It is clear that the observed increase in the number of cells is a factor in the glucose-driven response, with an approximately fourfold change across the glucose concentrations tested.

Second, focusing on the responding cells it is clear that glucose exerts a strong effect to increase the number of granule fusion events within each cell (Fig. 3c). We showed that the number of fused granules is glucose dependent, with a ninefold change (between 3 and $8 \mathrm{mmol} / \mathrm{l}$ glucose; $6,8,15$, $20 \mathrm{mmol} / \mathrm{l}$ glucose all significantly different from $3 \mathrm{mmol} / \mathrm{l}$ glucose, Student's $t$ test $p<0.01$ ).

How do our measures of numbers of granule fusion events compare with the amount of insulin secreted? We used an homogeneous time-resolved fluorescence (HTRF) assay to measure insulin secretion from four islets, in response to a range of glucose concentrations at 10,20 and $60 \mathrm{~min}$ (Fig. 3d, $n=4-6$ animals). The bar chart shows the maximal amount of insulin secreted in response to $15 \mathrm{mmol} / \mathrm{l}$ glucose at each of the times. The line graph normalised the responses (to maximal) and fitted a sigmoidal function. The estimated $\mathrm{EC}_{50}$ values for glucose were $7.95,9.97$ and $12.24 \mathrm{mmol} / \mathrm{l}$ at the times 10, 20 and $60 \mathrm{~min}$, respectively. This left shift in the $\mathrm{EC}_{50}$ at shorter time-frames of stimulation has been observed before [17] and is likely to reflect larger differences in the glucose dependence of the second phase of the response.

We can now directly compare measured insulin secretion with our observations of the number of granule fusion events as a means to validate our two-photon assay. Our two-photon slice samples a volume of $2,000 \mu \mathrm{m}^{3}(\sim 40 \times 50 \times 1 \mu \mathrm{m})$ and the approximate volume of an average islet is $1.6 \times 10^{6} \mu \mathrm{m}^{3}$ [27]. Our sample volume therefore represents $\sim 1 / 800$ of the total volume of an average islet. At $15 \mathrm{mmol} / \mathrm{l}$ glucose the mean number of granule fusion events in our two-photon sample volume is 33.1 within the $20 \mathrm{~min}$ recording $( \pm 4.26$, mean \pm SEM, $n=10$ islets). Scaled up this gives a total number of fusion events of 26,400 per islet. The amount of insulin contained in a single granule is $1.6 \times 10^{-18} \mathrm{~mol}$ per granule [28] $\left(9.25 \times 10^{-15} \mathrm{~g} /\right.$ granule $)$. Thus, based on our measures of granule fusion and the estimated amount of insulin in a granule we calculate that the total amount of insulin secretion is $0.244 \times 10^{-9} \mathrm{~g} /$ islet. This is in close agreement with our measures of insulin secretion, which were $0.175 \times 10^{-9} \mathrm{~g} /$ islet with $15 \mathrm{mmol} / 1$ glucose at $10 \mathrm{~min}$ and
$0.277 \times 10^{-9} \mathrm{~g} /$ islet at $20 \mathrm{~min}$; this validates our two-photon assay as an accurate measure of secretory output.

Single granule fusion events show complex spatial and temporal patterns within beta cells across an islet Having shown that the main drivers for glucose are increased recruitment of cells and increased exocytic responses within cells, then how is this manifest across an islet? To address this we conducted a detailed analysis of the timing and spatial position of each granule fusion event across cells within an islet $(n=4-6$ animals and $8-10$ islets for each glucose concentration). At $3 \mathrm{mmol} / \mathrm{l}$ glucose we observed occasional fusion events. These occurred throughout the recording period and were found in cells across our two-photon section (Fig. 4). Measurement of the average perimeter of the cells responding to $3 \mathrm{mmol} / \mathrm{l}$, show they were the same size as those cells that responded to $20 \mathrm{mmol} / \mathrm{l}$ glucose. This suggests that across the glucose dose range we are likely to be recording insulin granule fusion within beta cells (ESM Fig. 4).

Glucose at $6 \mathrm{mmol} / \mathrm{l}$ induced many more fusion events. These were clustered in time, giving rise to oscillations in activity. Importantly, these oscillations recruited multiple cells, all of which showed exocytic events within narrow time periods (Fig. 4). Finally, $15 \mathrm{mmol} / \mathrm{l}$ glucose induced many more events. These findings provide evidence for coordinated oscillatory activity across multiple cells within the islet.

Single granule fusion kinetics are not glucose dependent The analysis presented so far has counted the number of fusing granules and has not taken into account the possible dynamics of the granule fusion pore. To directly assess this we developed a method to quantify fusion pore closure. As this is the essential first step to granule recovery in the kiss-and-run model, our method is a direct test for these granule behaviours. Our method employs a technique to monitor granule acidification. As has been shown previously, recaptured granules rapidly re-acidify after fusion pore closure [29]. In our experiments we included two extracellular dyes, SRB and HPTS, the latter a $\mathrm{pH}$-sensitive extracellular dye [30]. These dyes move into the fused granules and any subsequent acidification, tracked as a selective decrease in the HPTS fluorescence, was used as an index of granule recapture (Fig. 5a). In most fusion events HPTS fluorescence closely followed the time course of SRB fluorescence. In fewer than $10 \%$ of all granule fusion events HPTS fluorescence decreased significantly away from the SRB fluorescence (Fig. 5a), indicating acidification and granule recapture. Across a range of glucose concentrations there was a slight but not significant (Student's $t$ test) trend to a greater proportion of granule recapture at higher glucose concentrations (Fig. 5b; $6 \mathrm{mmol} / \mathrm{l}, 11$ islets, 166 events; $8 \mathrm{mmol} / \mathrm{l}$, eight islets, 383 events; $15 \mathrm{mmol} / \mathrm{l}$, ten islets, 341 events; $20 \mathrm{mmol} / \mathrm{l}, 11$ islets, 420 events). 

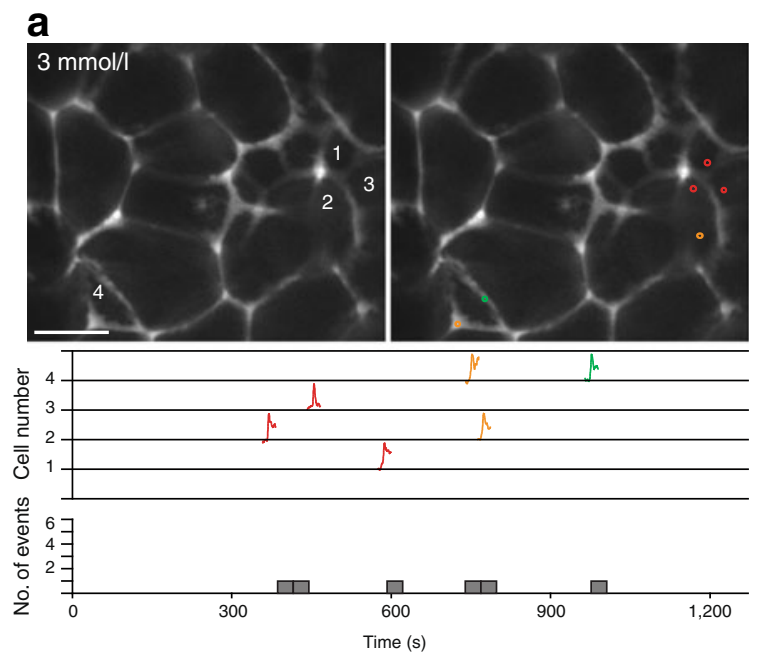

b
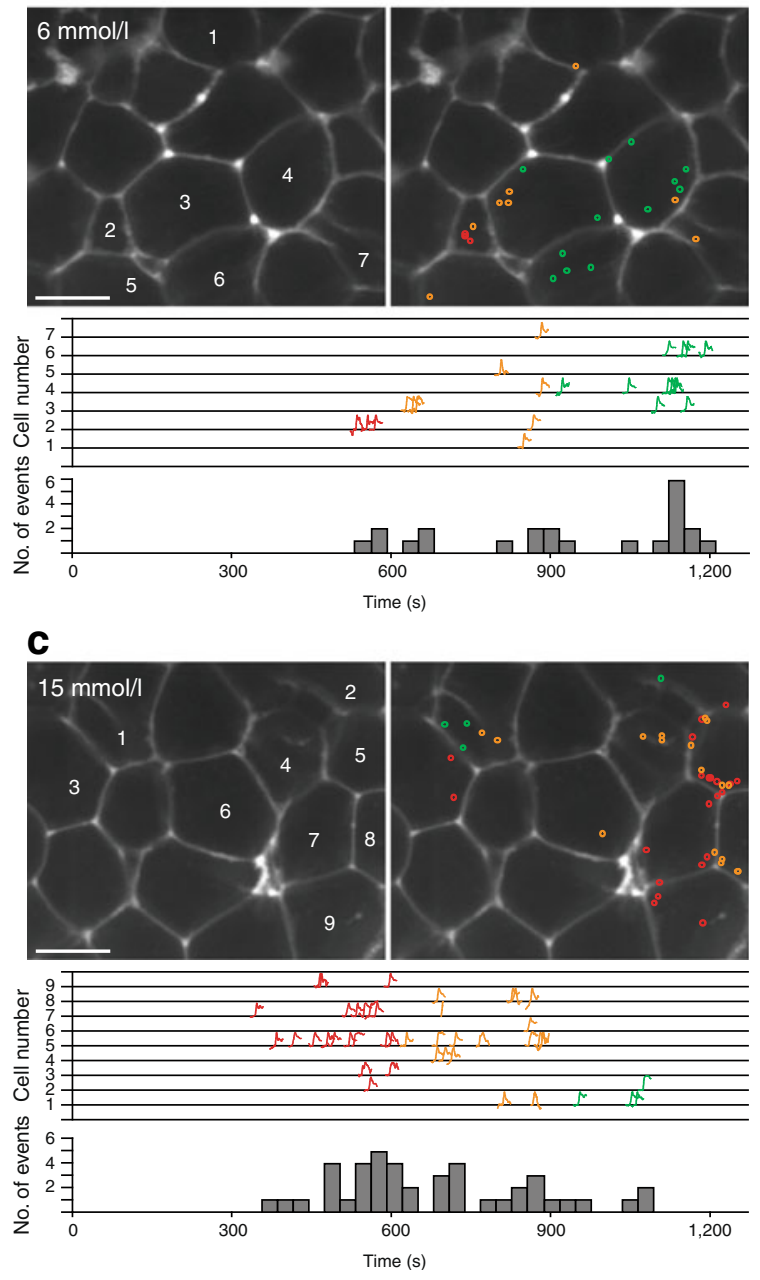

Whole-granule recapture within intact islets has been controversial and to further our analysis we performed electron microscopy on fixed islets. To assay for recapture we bathed living islets in horseradish peroxidase (HRP), stimulated with glucose and then washed with fresh extracellular buffer without HRP before fixing. HRP would therefore only be present in
Fig. 4 Spatial and temporal dependence of fusion events on glucose. Typical examples of the fusion events induced by (a) $3 \mathrm{mmol} / \mathrm{l}$, (b) $6 \mathrm{mmol} / \mathrm{l}$, and (c) $15 \mathrm{mmol} / \mathrm{l}$ glucose. In each case glucose was added at time 0 . In each panel the upper two images are the same fields of view. The left image numerically identifies each responding cell. The right image identifies each fusion event, observed over a $20 \mathrm{~min}$ time period, with colour-coded circles: red, 5-10 min; orange, 10-15 min; and green, 15-20 min. The graph for each glucose concentration shows a brief time sample (just before the event and a few seconds after) of the average fluorescent changes in $0.8 \mu \mathrm{m}$ regions of interest placed over each fusion event, colour coded as before. The histogram for each glucose concentration shows the number of fusion events occurring in $30 \mathrm{~s}$ time bins. These observed spatial and temporal glucose-dependent changes in exocytosis further confirm that we recorded the responses of beta cells. Scale bars, $10 \mu \mathrm{m}$

endocytic structures and in electron micrographs was present in various small endocytic compartments and in whole granules which were positively identified as insulin granules by the simultaneous presence of insulin crystals (Fig. 5 c, $n=3$ islets).

\section{Discussion}

Our two-photon imaging gave direct insights into the glucose dependence of single-cell secretory responses within intact islets. Past work looking at factors upstream in the stimulus-secretion cascade within intact islets has provided contrasting views. There is evidence for heterogeneous cell responses in terms of upregulation of insulin expression [8] and protein synthesis [1]. In contrast, the $\mathrm{NAD}(\mathrm{P}) \mathrm{H}[13]$ and calcium responses [14] to glucose appear much more homogeneous. We now show that increasing glucose concentration does recruit cells across the islet, providing evidence for heterogeneity. However, the dominant effect is an increase in the secretory response within cells and for the coordination of responses across cells. Furthermore, our data argue against the post-fusion behaviour of granules as a factor in glucose control. Our data add further evidence for the importance of cell-to-cell coordination within an islet and highlight recruitment of full granule fusion within single cells as the major factor under the control of glucose.

Identification of beta cells Many methods have been used in the study of exocytosis in beta cells. The main advantage of the method we use is the ability to record many exocytic events from many cells within intact islets. Our recordings are consistent with recording exocytosis of insulin-containing granules. Beta cells do contain synaptic-like microvesicles [31], but these are much smaller $(<100 \mathrm{~nm}$ diameter) than insulin granules and even if fusion was detectable they would be distinct from the $\sim 400 \mathrm{~nm}$ diameter granules we record (ESM Fig. 1). We might occasionally record from alpha cells. However, this is unlikely given their location on the periphery of rodent islets, inhibition of their responses with glucose and our data showing we record from cells of a consistent cell size (ESM Fig. 4). Indeed our estimates of beta cell area are almost 

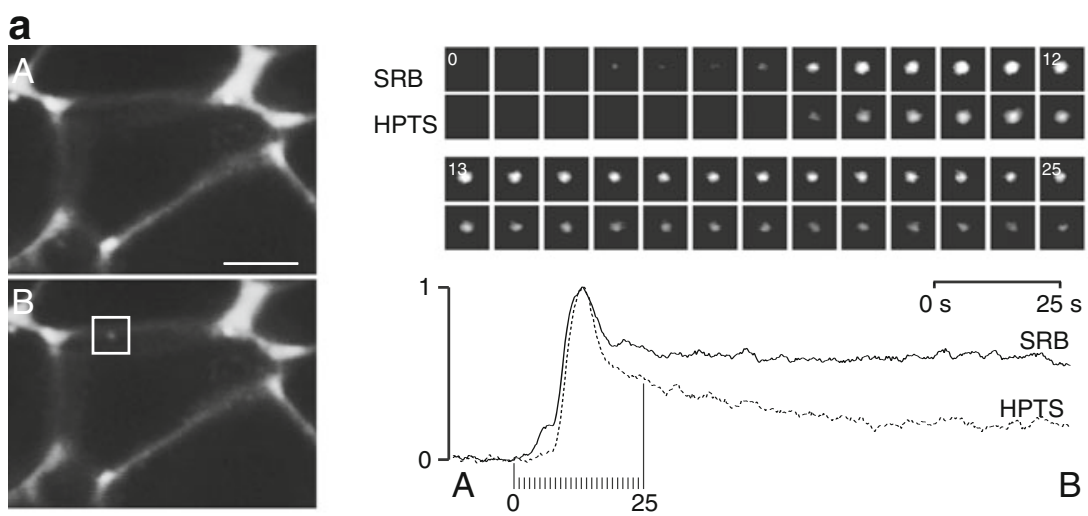

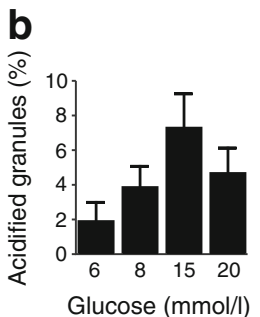

Fig. 5 Granule recapture measured in live cell and electron microscopy experiments. (a) SRB and HPTS dyes enter simultaneously into fusing granules. In most cases the dyes behaved with an identical kinetics. However, in a minority of granules the HPTS fluorescence was seen to decrease compared with SRB, which is indicative of granule acidification. An example of a low-magnification image (A, before the event, and $\mathrm{B}$, at the end of the event) is shown. The white square outlines a single event and the image sequences for both SRB and HPTS are shown (frames

identical to previous measures [32] and, as alpha cells are smaller, these are unlikely to contaminate our recordings.

The temporal and spatial occurrence of exocytosis reported here is also consistent with expected beta cell responses (Figs 2 and 4). The very close agreement between the amount of insulin secreted, based on calculations of the number of fusion events, and the actual amount of insulin secreted is a validation that our assay accurately records the fusion of insulin granules.

Single granule kinetics The evidence from single cells is that fusion of insulin granules is not necessarily all or none and that, once opened, the fusion pore is capable of closure $[18,33]$. The implication of these behaviours is that they might differentially control insulin secretion, with only partial release occurring before the fusion pore closes. The prevalence of these alternative behaviours in native islets is controversial, with two reports suggesting pore closure occurs only rarely, if at all [21, 22].

Our data provide strong new evidence to support the notion that the fusion pore can close in intact islets. We show that, after fusion, granules can re-acidify, and second we show HRP uptake in granules that contain insulin crystals. Quantification of granule acidification shows granule recapture is rare and occurs in fewer than $10 \%$ of all fusion events. Furthermore, this proportion does not change significantly across a range of glucose concentrations. If anything, there is a small increase in recaptured granules at higher glucose concentrations (Fig. 5). This trend is contrary to expectations as high glucose leads to an increase in insulin secretion and transient fusion would decrease insulin secretion. It is important to emphasise that our assay only records acidification in those granules where the pore has closed for a sufficiently long time for the proton pump to change granule acidity [34]. We therefore cannot measure fusion pore flickering or fusion pore diameters.

Our findings argue against a role for glucose in controlling granule dynamics. However, different forms of granule fusion may be a component in the differential release of lowmolecular-weight substances [35] and may, therefore, be part of mechanisms to couple cell-to-cell behaviour. Alternatively, different fusion behaviour may be associated with pathological responses [36].

Does our work have any implications for diabetes? One interesting outcome from our work is that it is glucose concentrations across a range from 3 to $8 \mathrm{mmol} / \mathrm{l}$ (Fig. 3) that appear to exert the major stimulatory effect on insulin granule exocytosis. This range is very close to the range of fasting to maximal glucose levels in both mouse $(5-10 \mathrm{mmol} / \mathrm{l})$ [37] and humans after a meal $(5-8 \mathrm{mmol} / \mathrm{l})$ [38] and indicates that normally the beta cells are operating within their optimal 
range of glucose concentrations. In contrast, in untreated type 2 diabetes, fasting blood glucose has been measured as $9 \mathrm{mmol} / \mathrm{l}$, rising to $>11 \mathrm{mmol} / \mathrm{l}$ after a meal [39] —a range of glucose concentrations that our data indicate would have a minimal effect in stimulating further insulin secretion. This shift away from the optimal stimulatory range of glucose is therefore likely to be a further factor in the development of the disease.

Finally, our work directly quantifies glucose-induced cell recruitment vs an increased cellular response and shows the latter is more significant within the context of the islet. It is likely that a similar situation exists in human islets. However, given the differences in human vs rodent islet architecture [24], innervation [40], cell-to-cell communication [41] and GLUT2 expression [42], we would anticipate that the details of the response would be different. It will be interesting to apply our techniques to the measure of insulin secretion in human islets.

Funding This work was supported by an Australian Research Council Grant DP110100642 (to Peter Thorn) and a National Health and Medical Research Council Grant APP1002520 (to Peter Thorn and Herbert Y. Gaisano).

Contribution statement All authors made substantial contributions to the conception and design of the experiments. JTW, JMM, OHD, JB, AR and MZ performed research. GM and RGP developed the methods. HYG and PT designed the research. All authors were involved in drafting the manuscript and all approved the final version.

Duality of interest The authors confirm there is no duality of interest associated with this manuscript.

Open Access This article is distributed under the terms of the Creative Commons Attribution Noncommercial License which permits any noncommercial use, distribution, and reproduction in any medium, provided the original author(s) and the source are credited.

\section{References}

1. Schuit FC, Tveld PAI, Pipeleers DG (1988) Glucose stimulates proinsulin biosynthesis by a dose-dependent recruitment of pancreatic beta-cells. Proc Natl Acad Sci U S A 85:3865-3869

2. Schuit FC, Kiekens R, Pipeleers DG (1991) Measuring the balance between insulin synthesis and insulin release. Biochem Biophys Res Comm 178:1182-1187

3. Heimberg H, Devos A, Vandercammen A, Vanschaftingen E, Pipeleers D, Schuit F (1993) Heterogeneity in glucose sensitivity among pancreatic beta-cells is correlated to differences in glucose phosphorylation rather than glucose-transport. EMBO J 12:28732879

4. Jonkers FC, Henquin JC (2001) Measurements of cytoplasmic Ca2+ in islet cell clusters show that glucose rapidly recruits beta-cells and gradually increases the individual cell response. Diabetes 50:540 550
5. Salomon D, Meda P (1986) Heterogeneity and contact-dependent regulation of hormone-secretion by individual b-cells. Exp Cell Res 162:507-520

6. Gembal M, Gilon P, Henquin JC (1992) Evidence that glucose can control insulin release independently from its action on ATP-sensitive $\mathrm{K}^{+}$channels in mouse $\beta$-cells. J Clin Invest 89:1288-1295

7. Pipeleers D, Kiekens R, Ling Z, Wilikens A, Schuit F (1994) Physiological relevance of heterogeneity in the pancreatic beta cell population. Diabetologia 37(Suppl):S57-S64

8. deVargas LM, Sobolewski J, Siegel R, Moss LG (1997) Individual beta cells within the intact islet differentially respond to glucose. J Biol Chem 272:26573-26577

9. Benninger RKP, Head WS, Zhang M, Satin LS, Piston DW (2011) Gap junctions and other mechanisms of cell-cell communication regulate basal insulin secretion in the pancreatic islet. J Physiol 589:5453-5466

10. Halban PA, Wollheim CB, Blondel B, Meda P, Niesor EN, Mintz DH (1982) The possible importance of contact between pancreatic-islet cells for the control of insulin release. Endocrinology 111:86-94

11. Gopel S, Zhang Q, Eliasson L et al (2004) Capacitance measurements of exocytosis in mouse pancreatic alpha-, beta- and delta-cells within intact islets of Langerhans. J Physiol 556:711-726

12. Ravier MA, Guldenagel M, Charollais A et al (2005) Loss of connexin36 channels alters beta-cell coupling, islet synchronization of glucose-induced $\mathrm{Ca} 2+$ and insulin oscillations, and basal insulin release. Diabetes 54:1798-1807

13. Bennett BD, Jetton TL, Ying GT, Magnuson MA, Piston DW (1996) Quantitative subcellular imaging of glucose metabolism within intact pancreatic islets. J Biol Chem 271:3647-3651

14. Benninger RKP, Zhang M, Head WS, Satin LS, Piston DW (2008) Gap junction coupling and calcium waves in the pancreatic islet. Biophys J 95:5048-5061

15. Zhang Q, Galvanovskis J, Abdulkader F et al (2008) Cell coupling in mouse pancreatic beta-cells measured in intact islets of Langerhans. Philos Trans A Math Phys Eng Sci 366:3503-3523

16. Ashcroft FM, Rorsman P (2012) Diabetes mellitus and the beta cell: the last ten years. Cell 148:1160-1171

17. Henquin JC, Nenquin M, Stiernet P, Ahren B (2006) In vivo and in vitro glucose-induced biphasic insulin secretion in the mouse - pattern and role of cytoplasmic $\mathrm{Ca} 2+$ and amplification signals in beta-cells. Diabetes 55:441-451

18. MacDonald PE, Braun M, Galvanovskis J, Rorsman P (2006) Release of small transmitters through kiss-and-run fusion pores in rat pancreatic beta cells. Cell Metab 4:283-290

19. Tsuboi T, McMahon HT, Rutter GA (2004) Mechanisms of dense core vesicle recapture following 'kiss and run' ('cavicapture') exocytosis in insulin-secreting cells. J Biol Chem 279:47115-47124

20. Doreian BW, Fulop TG, Meklemburg RL, Smith CB (2009) Cortical $\mathrm{f}$-actin, the exocytic mode, and neuropeptide release in mouse chromaffin cells is regulated by myristoylated alanine-rich c-kinase substrate and myosin II. Mol Biol Cell 20:3142-3154

21. Ma L, Bindokas VP, Kuznetsov A et al (2004) Direct imaging shows that insulin granule exocytosis occurs by complete vesicle fusion. Proc Natl Acad Sci U S A 101:9266-9271

22. Takahashi N, Kishimoto T, Nemoto T, Kadowaki T, Kasai H (2002) Fusion pore dynamics and insulin granule exocytosis in the pancreatic islet. Science 297:1349-1352

23. Thorn P, Fogarty KE, Parker I (2004) Zymogen granule exocytosis is characterized by long fusion pore openings and preservation of vesicle lipid identity. Proc Natl Acad Sci U S A 101:6774-6779

24. Kim A, Miller K, Jo J, Kilimnik G, Wojcik P, Hara M (2009) Islet architecture a comparative study. Islets 1:129-136

25. Kwan EP, Gaisano HY (2005) Glucagon-like peptide 1 regulates sequential and compound exocytosis in pancreatic islet beta-cells. Diabetes 54:2734-2743 
26. Hoppa MB, Jones E, Karanauskaite J et al (2012) Multivesicular exocytosis in rat pancreatic beta cells. Diabetologia 55:1001-1012

27. Bock T, Svenstrup K, Pakkenberg B, Buschard K (1999) Unbiased estimation of total beta-cell number and mean beta-cell volume in rodent pancreas. APMIS 107:791-799

28. Huang L, Shen H, Atkinson MA, Kennedy RT (1995) Detection of exocytosis at individual pancreatic beta-cells by amperometry at a chemically-modified microelectrode. Proc Natl Acad Sci U S A 92:9608-9612

29. Ohara-Imaizumi M, Nakamichi Y, Tanaka T, Katsuta H, Ishida H, Nagamatsu S (2002) Monitoring of exocytosis and endocytosis of insulin secretory granules in the pancreatic beta-cell line MIN6 using $\mathrm{pH}$-sensitive green fluorescent protein (pHluorin) and confocal laser microscopy. Biochem J 363:73-80

30. Behrendorff N, Floetenmeyer M, Schwiening C, Thorn P (2010) Protons released during pancreatic acinar cell secretion acidify the lumen and contribute to pancreatitis in mice. Gastroenterology 139:1711-1719

31. Reetz A, Solimena M, Matteoli M, Folli F, Takei K, Decamilli P (1991) GABA and pancreatic beta-cells: colocalization of glutamicacid decarboxylase (GAD) and GABA with synaptic-like microvesicles suggests their role in GABA storage and secretion. EMBO J 10:1275-1284

32. Gopel SO, Kanno T, Barg S, Rorsman P (2000) Patch-clamp characterisation of somatostatin secreting delta-cells in intact mouse pancreatic islets. J Physiol 528:497-507

33. Rutter GA, Tsuboi T (2004) Kiss and run exocytosis of dense core secretory vesicles. Neuroreport 15:79-81

34. Ohara-Imaizumi M, Fujiwara T, Nakamichi Y et al (2007) Imaging analysis reveals mechanistic differences between first- and secondphase insulin exocytosis. J Cell Biol 177:695-705
35. Braun M, Wendt A, Karanauskaite J et al (2007) Corelease and differential exit via the fusion pore of GABA, serotonin, and ATP from LDCV in rat pancreatic beta cells. J Gen Physiol 129:221-231

36. Olofsson CS, Collins S, Bengtsson M et al (2007) Long-term exposure to glucose and lipids inhibits glucose-induced insulin secretion downstream of granule fusion with plasma membrane. Diabetes 56:1888-1897

37. Klueh U, Liu ZH, Cho B et al (2006) Continuous glucose monitoring in normal mice and mice with prediabetes and diabetes. Diabetes Techn Therap 8:402-412

38. Juntunen KS, Niskanen LK, Liukkonen KH, Poittanen KS, Holst JJ, Mykkanen HM (2002) Postprandial glucose, insulin, and incretin responses to grain products in healthy subjects. Am J Clin Nutr 75:254-262

39. Bonora E, Calcaterra F, Lombardi S et al (2001) Plasma glucose levels throughout the day and $\mathrm{HbA}_{1 \mathrm{c}}$ interrelationships in type 2 diabetes - implications for treatment and monitoring of metabolic control. Diabetes Care 24:2023-2029

40. Rodriguez-Diaz R, Abdulreda MH, Formoso AL et al (2011) Innervation patterns of autonomic axons in the human endocrine pancreas. Innervation patterns of autonomic axons in the human endocrine pancreas. Cell Metab 14:45-54

41. Jacques-Silva MC, Correa-Medina M, Cabrera O et al (2010) ATPgated $\mathrm{P} 2 \mathrm{X}(3)$ receptors constitute a positive autocrine signal for insulin release in the human pancreatic beta cell. Proc Natl Acad Sci U S A 107:6465-6470

42. De Vos A, Heimberg H, Quartier E et al (1995) Human and rat beta cells differ in glucose transport but not in glucokinase expression. J Clin Invest 96:2489-2495 